\title{
Metaheurística Evolutiva para o Problema de Sequenciamento de Aviões de uma companhia Aérea entre Origens e Destinos.
}

\section{Aluno: William H. Shie Professora Responsável: Priscila B. Rampazzo}

\section{Resumo}

O objetivo deste projeto é propor e implementar uma Metaheurística Evolutiva (baseada em Algoritmo Genético) para o Problema de Sequenciamento de Aviões de uma Companhia Aérea Entre Origens e Destinos. Utilizou-se, para este propósito, de um algoritmo, implementado em linguagem $\mathrm{C}$, que considera o problema com múltiplos objetivos e gera um conjunto de soluções para posterior tomada de decisão.

\section{Palavras-chave:}

Sequenciamento de Aviões, Algoritmos Genéticos, Metaheurísticas

\section{Introdução}

O Problema de Sequenciamento de Aviões de uma Companhia Aérea entre Origens e Destinos (Fleet Assignment) pode ser definido como: Dado um mapa aéreo de possíveis trajetos de vôos, alocar para cada rota (definida por origem, destino, distância) um tipo de avião, cada qual com características próprias como custo operacional (por distância), disponibilidade, quantidade, receita prevista, etc. de modo que minimize o custo total ou, por conseguinte, maximize o lucro potencial. Neste trabalho, buscou-se estudar o problema por meio de estudo de um caso simplificado utilizando uma metaheurística evolutiva multi-objetivo para obtenção de soluções alternativas.

\section{Resultados e Discussão}

Para a modelagem deste problema baseou-se na formulação matemática proposta por Abara (1989).

$$
\begin{aligned}
& \max \sum_{i \in L \cup\{0\}} \sum_{j \in L} \sum_{f \in F} p_{j f} x_{i j f}-c \sum_{j \in L} \sum_{f \in F} x_{0 j f} \\
& \text { s.a } \quad \sum_{i \in L \cup\{0\}} \sum_{f \in F} x_{i j f}=1 \quad \forall j \in L \\
& \sum_{i \in L \cup\{0\}} x_{i l f}-\sum_{j \in L \cup\{0\}} x_{l j f}=0 \quad \forall l \in L, f \in F \\
& \sum_{i \in D_{s}} x_{0 i f}-\sum_{i \in A_{s}} x_{i 0 f}=0 \quad \forall s \in S, f \in F \\
& \sum_{i \in L} x_{0 i f} \leqslant A_{f} \quad \forall f \in F \text {. } \\
& x \in\{0,1\} \quad \forall j
\end{aligned}
$$

Para adequar-se a um contexto mais realista, o modelo foi modificado para considerar duas funções-objetivo, uma relacionada ao balanceamento do tempo de viagem entre todos os aviões e outra em relação a diferença entre as rotas reais realizadas e as rotas propostas. As restrições consideradas são referentes a equações de balanceamento das rotas.

Para a criação da metaheurística evolutiva, utilizou-se como base um algoritmo genético com população de tamanho $\boldsymbol{p}$ e quantidade de gerações $\boldsymbol{g}$ definidas empiricamente. A inicialização do algoritmo ocorre com a geração de $\boldsymbol{p}$ indivíduos (soluções) aleatórios, cada qual representando um sequenciamento de todos os aviões disponíveis, após esse processo, essa população então é sujeita aos processos de torneio, crossover, mutação, sequencialmente, resultando-se na população de filhos. O processo de torneio é binário: 2 indivíduos aleatórios competem em relação às suas funções-objetivo (uma solução domina a outra se não é pior em nenhum dos objetivos e é melhor em pelo menos um). Escolhe-se então pares de pais para gerar a próxima geração. Após este processo, realiza-se o crossover, operador probabilístico que cria a população de filhos através do cruzamento das soluções selecionadas no torneio. Realizada estas etapas, pode ocorrer o processo de mutação (busca ou melhoramento local), onde existe um realocamento de rotas do avião com maior tempo de vôo para o com menor tempo de vôo. A próxima geração é escolhida de acordo com critérios de não-dominância (Otimização Multiobjetivo) e diversidade. Este processo é repetido por $\mathbf{g}$ gerações, chegando assim em um conjunto de soluções alternativas.

Tabela 1. Exemplo com populações de 4 indivíduos

\begin{tabular}{|l|l|l|}
\hline Indivíduo & Função Objetivo 1 & Função Objetivo 2 \\
\hline Pai1 & 1105 & 25.612505 \\
\hline Pai2 & 1184 & 21.478168 \\
\hline Pai3 & 1143 & 28.500713 \\
\hline Pai4 & 1162 & 22.455673 \\
\hline Filho1 & 1145 & 24.931803 \\
\hline Filho2 & 1155 & 25.535830 \\
\hline Filho3 & 1143 & 28.500713 \\
\hline Filho4 & 1143 & 28.500713 \\
\hline
\end{tabular}

\section{Conclusões}

Dada a complexidade do problema, optou-se pela abordagem metaheurística, que é capaz de representar as particularidades do problema sem a necessidade explícita de uma representação através de funções matemáticas. A abordagem multiobjetivo se aproxima da realidade complexa, permitindo a obtenção de um conjunto de soluções para que um decisor possa escolher a melhor alternativa.

\section{Agradecimentos}

Agradeço a PIBIC/CNPq pela bolsa de iniciação científica e pela oportunidade de conhecer o meio científico.

1 ABARA, J. Applying integer linear programming to the fleet assignment problem. v. 19, p. 20-28, 021989 . 